\title{
Treatment of trichomoniasis with metronidazole rectal suppositories
}

\author{
S K PANJA \\ From the Department of Genitourinary Medicine, Royal Infirmary, Cardiff
}

SUMMARY Since a single dose of metronidazole in suppository form is very effective in the prevention of postoperative Gram-negative anaerobic infections, 84 patients with vaginal trichomoniasis were treated with metronidazole suppositories (two 1-g suppositories in a single dose). The cure rate in this series was $94 \%$.

\section{Introduction}

Metronidazole is the drug of choice in the treatment of trichomoniasis. A single oral dose of $2 \mathrm{~g}$ metronidazole achieves a high cure rate. ${ }^{12}$ The use of metronidazole suppositories is useful in the prevention of postoperative infections. ${ }^{34}$ Within two hours of insertion into the rectum $2 \mathrm{~g}$ metronidazole in suppository form produces a serum concentration of $4 \mu \mathrm{g} / \mathrm{ml} .^{56}$ After reaching a peak concentration of $12-20 \mu \mathrm{g} / \mathrm{ml}$ in about eight hours, the serum concentration of metronidazole falls slowly to about $4 \mu \mathrm{g} / \mathrm{ml}$ in 24 hours. ${ }^{7}$ Since in-vitro tests have shown that most strains of Trichomonas vaginalis are killed when the concentration of metronidazole in the surrounding medium is between $0.25 \mu \mathrm{g} / \mathrm{ml}$ and $1 \cdot 25 \mu \mathrm{g} / \mathrm{ml}$, a $2-\mathrm{g}$ rectal dose should be effective in the treatment of trichomoniasis. As a prolonged course of any medication results in poor patient compliance, treatment with a suppository which is completed in the clinic may be invaluable in eradicating vaginal trichomoniasis.

\section{Patients and methods}

Eighty-four women with vaginal trichomoniasis attending the department of genitourinary medicine from May 1980 to August 1981 were studied. Patients included in the project were unselected. The appropriate microbiological investigations were undertaken to confirm or exclude the presence of gonorrhoea, syphilis, candidosis, chlamydial infection, and Herpesvirus hominis infection. Cervical cytology was performed routinely. Vaginal secretions were examined by direct microscopy and culture for infection with $T$ vaginalis.

Address for reprints: Dr S K Panja, Department of Genitourinary Medicine, Royal Infirmary, Cardiff

Accepted for publication 3 March 1982

\section{TREATMENT}

When trichomoniasis had been diagnosed, the women were treated with metronidazole suppositories. A lubricated plastic proctoscope was inserted into the rectum, through which the suppositories (total dose of $2 \mathrm{~g}$ metronidazole) were introduced. The patients were asked to refrain from sexual activity for at least one week.

\section{FOLLOW UP}

The patients were examined at one week and four weeks after treatment. At the follow-up examinations, microscopy and cultures for $T$ vaginalis and $C$ albicans were performed and other investigations undertaken when necessary. The women were asked leading questions about the side effects and the acceptability of the treatment. The patients who had been reinfected were treated with $2 \mathrm{~g}$ metronidazole suppositories and those who were regarded as treatment failures were given $\mathbf{2 0 0}$ mg metronidazole orally three times a day for seven days.

\section{SEXUAL CONTACTS}

Forty-nine men who were named contacts of the women in the study attended the department and were treated empirically with $\mathbf{2 0 0} \mathrm{mg}$ metronidazole orally three times daily for seven days. The female patients were asked not to take any of the tablets which had been given to their consorts.

\section{Results}

Trichomoniasis was diagnosed by direct microscopy in three $(3 \cdot 6 \%)$ women, by culture in four $(4 \cdot 8 \%)$, and by both microscopy and culture in $77(91 \cdot 7 \%)$.

The mean age of the patients was $23 \cdot 1$ (range 14-49) years; 12 were married; 28 used oral contraception, 44 took no contraceptive precautions, and the remainder used other methods. 
Concomitant infection with gonorrhoea was diagnosed in $24 \%$ of these women; $19 \%$ had candidosis, $7 \%$ had genital herpes, and $6 \%$ had genital warts.

\section{TREATMENT}

The results of treatment with metronidazole suppositories are shown in table I; five patients did not return for follow up one week after treatment had been given.

TABLE I Results of treatment of trichomoniasis with metronidazole suppositories at follow up seven days after treatment

\begin{tabular}{llll}
\hline $\begin{array}{l}\text { Total No } \\
\text { of patients }\end{array}$ & $\begin{array}{l}\text { Primary } \\
\text { failure (\%) }\end{array}$ & Reinfected (\%) & Cured (\%) \\
\hline 79 & $5(6)$ & $6(7)$ & $74(94)$ \\
\hline
\end{tabular}

Reinfection occurred in patients who had had sexual intercourse within seven days of treatment either with a new partner or with an untreated regular partner. All six of these women were treated successfully with a second dose of rectal metronidazole.

The five women who were considered to have had primary failure of the drug regimen were treated with oral metronidazole; this was not successful in one woman. The strain of $T$ vaginalis isolated from her vagina had a minimum inhibitory concentration (assessed under anaerobic conditions) of $48 \mu \mathrm{g} / \mathrm{ml}$. She was treated with hydrargaphen pessaries $3 \mathrm{mg}$ at night for $\mathbf{2 8}$ days. Four months after completion of this regimen trichomonads were not present in the vaginal secretions.

Suppository treatment for trichomoniasis failed in two of five women who developed diarrhoea within one hour of insertion.

FOLLOW UP

Sixty-seven patients attended for follow up four weeks after treatment; of these 12 had trichomoniasis. After consideration of their histories, nine women had been reinfected and three had had a relapse, for which no identifiable cause was found.

The side effects of treatment are shown in table II.

TABLE II Side effects in 79 patients treated with metronidazole in a single rectal dose

\begin{tabular}{lc}
\hline Side effects & No of cases (\%) \\
\hline None & $61(77)$ \\
Nausea & $5(6)$ \\
Unpleasant taste & $4(5)$ \\
Diarrhoea & $5(6)$ \\
Abdominal discomfort & $3(4)$ \\
Vomiting & $1(1)$ \\
\hline
\end{tabular}

\section{Discussion}

Metronidazole is well established as the drug of $\frac{\nabla}{\omega}$. choice in the treatment of trichomoniasis; its use by the rectal route has not been previously reported. It is widely used postoperatively in surgery and gynae- 0 cology. ${ }^{347}$ The drug is extremely well absorbed from 으 the rectum, and in two hours attains a trichomonacidal $\frac{\bar{\rho}}{\bar{\sigma}}$ concentration in the plasma, which is maintained for $\stackrel{\mathbb{Q}}{\Omega}$ at least 24 hours. The single-dose rectal treatment is 0 completed in the clinic, is cheaper than oral treatment, has a high acceptability rate, and minimises $\vec{\circ}$ irregular and incomplete treatment (62 patients $\overrightarrow{\vec{\omega}}$ found that treatment by the rectal route was $\stackrel{\omega}{\omega}$ acceptable). The use of a plastic proctoscope helps in $\stackrel{\text { ? }}{=}$ positioning the suppository high in the rectum; this is prevents early bowel movement. In this series a cure ${ }_{A}^{\infty}$ rate of $94 \%$ was achieved. Thus, metronidazole i suppositories appear to have a definite place as an $y$ alternative to oral treatment. Women with gonor-응 rhoea require rectal examinations in the clinic and they may be treated for trichomoniasis at the same time.

I thank Dr L Cohen for his permission to report on $\vec{\varphi}$ these patients under his care.

\section{References}

1. Lossick J. Single dose metronidazole treatment for vaginal tri- $\overline{\bar{O}}$ chomoniasis. Obstet Gynecol 1980; 56:508-10.

2. Hager W, Brown S, Kraus S. Metronidazole for vaginal tri- 응 chomoniasis Seven-day vs single-day regimens. JAMA 1980; @ 244:1219-20.

3. Goulton J, Baker PG. Multicentric study of flagyl suppository in the prevention of postoperative anaerobic infection. $J$ Int Med Res 1978;6:471-5.

4. Rodgers J, Ross D, McNaught W. Intrarectal metronidazole in the prevention of anaerobic infection after emergency appendicectomy: a controlled clinical trial. Br J Surg 1979; के 66:425-7.

5. Houghton G, Templeton R. Statistical analysis of serum metronidazole levels in patients receiving the drug daily by 3 suppository. J Antimicrob Chemother $1978 ; 4$ suppl C:91-6.

6. Ioannides L, Somogyi A, Spicer J, et al. Rectal administration $O$ of metronidazole provides therapeutic plasma levels in postoperative patients. N Engl J Med 1981;305: 1569-70.

7. Jackson P, Ridley W, Pattison NS. Single-dose metronidazole prophylaxis in gynaecological surgery. NZ Med $J$ 1979; 89:243-5. 